\title{
Inquiry into clinical trial scandal at Canadian research hospital
}

Following morethan two years of repeated requests by research scientists and clinicians at the Hospital for Sick Children (HSC) in Toronto, Canada for an independent inquiry into a controversial clinical trial, the Board of Trustees announced on September 9th that such an investigation has been commissioned and the results will be made public on or after November 30th. HSC is widely recognized to be one of the premier biomedical research institutions in North America.

The conflict surrounds an HSC senior scientist, Nancy Olivieri, and her study of deferiprone-a drug with the potential to treat iron overload in beta-thalassemia patients who require repeated blood transfusions. Olivieri's discovery that the drug may cause serious side effects after longterm use, and the suspension of the trial by drug manufactures Apotex, have plunged HSC into a mire of problems.

Tension over the 'Apotex affair' has mounted into alleged legal threats, an internal email slander campaign, fears for jobs and a petition for an external inquiry signed by 120 HSC staffsome of whom threatened to take their research el sewhere

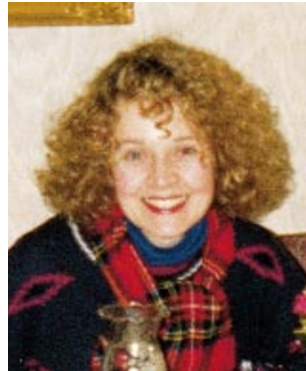
Nancy Olivieri

want to [listen]."

Olivieri contacted the HSC Research Ethical Board, which ordered her to change the informed consent forms for the trial and to make the data known to other sites. Olivieri complied and 72 hours later Apotex halted the trial at HSC and removed her from the project. Gallie believes that although Apotex had a legal right to stop the studies, their behavior was not appropriate: "the trial should have been modified to take into account the new data. By stopping the trial, the patient's efforts in volunteering to take an experimental drug were wasted."

Olivieri told Nature Medicine that the company threatened legal action if she made her concerns public but she persisted and Olivieri and Brittenham published their findings this August (NEJM , 339, 417; 1998). The data showed that although defiprone is initially successful in lowering iron load its effectiveness wanes in around 39 percent of patients.

More importantly, the researchers reported evidence of liver fibrosis in some of the patients. According to David Nathan, president of the Dana Farber Cancer Institute and the world's if the hospital administration continued to ignore their requests. "It is a profound and terrible problem that will only be resolved by a full external review," says Brenda Gallie, director of the HSC Cancer and Blood Research Center.

As a potentially new orally effectiveiron chelator, there was early enthusiasm for deferiprone. An initial study by Olivieri funded by the Canadian Medical Research Council and US National Institutes of Health showed that the drug was effective in lowering iron levels in patients (NEJM,332, 918; 1995). Based on these results, Olivieri signed a confidentiality agreement with Apotex in 1995 to head an international research effort that included trials at three sites-Canada, Italy and the US, collectively known as the L-1 trials-to assess the drug's efficacy and safety.

But one year into the trial the problems started. According to Olivieri's collaborator Gary Brittenham of Case Western Reserve University, "liver iron levels were increasing in some patients and when we told the company about it they did not leading expert in thalassemia, "iron overload in thalassemia patients does not induce significant fibrosis therefore the extra fibrosis [reported by Olivieri] may be due to the drug. This is a warning and this is how I am taking it." Apotex, however, maintains that the scientific data was not properly interpreted.

Although researchersfrom Canada have discontinued deferiprone therapy in all patients, including those for whom conventional treatment does not work, the drug is reported to have been approved for use in India and is currently undergoing Phase III studies in Italy.

Olivieri and Gallie claim they were verbally attacked by some members of HSC staff over the controversy. But what has been most disturbing to their colleagues is that Olivieri received no backing from HSC and the hospital has refused to provide her with a lawyer. John Dick, a specialist in hematopoietic stem cells at HSC, has sent documents to the Board in the past few weeks describing the action of the HSC administration as "inadequate."
Meanwhile, Nathan insists that this entire situation would have never arisen at his institution and believes that the hospital should have taken responsibility. "When the drug company threatened to sue Olivieri the hospital never told them to buzz off. They should have never let this happen," says Nathan.

Aside from a lack of support for a senior member of staff, there are other disturbing elements that call for a full investigation into clinical trial practices at HSC. According to Olivieri, data from her research was used without her permission by a fellow HSC researcher, Gideon Kramer, who is named by Apotex in their bid to obtain licensing approval for the drug. And Olivieri herself was a consultant for the company at the time the trial began-a conflict of interest that was ignored by all parties.

Furthermore, it is believed that Michael Spino, vice president of Apotex, has maintained a research laboratory at the hospital-a charge denied by HSC even though Spino's name appears on HSC letterhead and he was said to have been supervising a graduate student. "This would signal a much closer relationship between the academic unit and the company than simply one of funding," says Michelle Brilledwards, former assistant medical director for the Bureau of Human Prescription Drugs at the Health Protection Branch in Ottawa-the Canadian equival ent of the US Food and Drug Administration.

The external investigation will be directed by Arnold Naimark, formerly dean of medicine and president and vice chancellor of the University of Manitoba. Apotex has declared its support for the review and states that "there are over 300 published papers and abstracts on deferiprone to be considered along with Dr. Olivieri's report." But Olivieri told Nature Medicine that Naimark's appointment was without staff consultation and she will not cooperate with the inquiry because he has strong corporate allegiances.

Following the L-1 review, a second phase of investigation into general policies and procedures associated with trials at HSC is also scheduled. "This is what we have been asking for over two years. The outcome of this investigation will bevery instructivenot only for [HSC] but for research institutes all over Canada," says Dick.

Laura Bonetta, New York 